\title{
Paleointensities from Tertiary basalts, Inner Mongolia and Hebei Province, northeastern China
}

\author{
Hidefumi Tanaka ${ }^{1}$, Naho Takahashi ${ }^{1}$, and Zhong Zheng $^{2}$ \\ ${ }^{1}$ Kochi University, Faculty of Education, Kochi 780-8520, Japan \\ ${ }^{2}$ Sogokaihatsu Co. Ltd., Nishi-Koiwa, Edogawa-ku, Tokyo 133-0057, Japan \\ (Received October 3, 2006; Revised February 1, 2007; Accepted February 2, 2007; Online published July 20, 2007)
}

\begin{abstract}
A paleointensity study using the Thellier's method was made on Tertiary basaltic rocks in Inner Mongolia and Hebei Province, northeastern China. K-Ar ages were previously reported for all the rocks, which range around 6-8 Ma and 28-32 Ma. Sample selection was based on total quality of remanence behavior and rock magnetism. High stability to AF and thermal demagnetization, small difference between the heating and cooling curves of magnetic susceptibility vs. temperature measurements, and PSD to SD characteristics in the Day plot of the hysteresis parameters were required. Experiments in vacuum using Coe's procedure were applied to 54 specimens from nine flows. Experiments were successful for 34 specimens, giving seven flow mean paleointensities. Excluding two flow means (in one flow, only two specimens from the same sample survived and in the other, the within-site error amounts to 42\%) the final success rate was 29 out of 54 (54\%), which is not low. The obtained results range from 54 to $65 \mu \mathrm{T}$, except for one lava which gave $23 \mu \mathrm{T}$. These results indicate that although the paleointensity in the Tertiary was generally smaller than the present-day value, there were large fluctuations in the dipole moment, and paleointensities of the present-day level were often attained.
\end{abstract}

Key words: Paleointensity, Tertiary, Inner Mongolia, China, basalt.

\section{Introduction}

Recent comprehensive focus by the research community to paleointensity studies on volcanic rocks has resulted in a remarkable increase in the database, which now has 3128 data from 215 references in the most updated version of Pint03 by Perrin and Schnepp (2004) compared to 1123 data from 83 references in the first version by Tanaka et al. (1995). Nevertheless, controversy still continues on some of the most important questions, such as was the paleointensity during the Cretaceous normal superchron small or large?, and is the present-day dipole moment typical of the past or much larger than the average? Paleointensity data filtered with recent stringent criteria indicate that the paleointensity was much weaker than the present-day value for most of geological time (Selkin and Tauxe, 2000). However, this is still a matter of debate, and the research community is far from attaining a consensus (e.g., Biggin and Thomas, 2003; Heller et al., 2003). Obviously more data are necessary from various sources for a wide range of time. This paper aims to contribute to Tertiary paleointensity data by reporting results from basalt lavas of Inner Mongolia and Hebei Province, northeastern China. Samples were taken from the collection of Zheng et al. (1991). K-Ar ages of the samples were reported by Zheng et al. (2002) and range around 6-8 Ma and 28-32 Ma.

Copyright (c) The Society of Geomagnetism and Earth, Planetary and Space Sciences (SGEPSS); The Seismological Society of Japan; The Volcanological Society of Japan; The Geodetic Society of Japan; The Japanese Society for Planetary Sciences; TERRAPUB.

\section{Samples}

Basalt platforms are sporadically found over eastern China as shown in Fig. 1, which are mostly in Cenozoic age (re-drawn from Cheng et al. (1990)). Some of the basaltic rocks in Inner Mongolia and Hebei Province were paleomagnetically studied by Zheng et al. (1991). These samples were later dated using the K-Ar method (Zheng et al., 2002), giving ages which are mostly Tertiary, except for one platform of Cretaceous age. The 92 Ma Cretaceous samples were used for Thellier's paleointensity study by two groups (Tanaka and Kono, 2002; Zhao et al., 2004), both giving small paleointensities for the Cretaceous normal superchron. Our study takes the Tertiary samples from Zheng's collection for Thellier's paleointensity experiments. Most samples used are taken from Weickang basalts near Chifeng, except for one which is from Hannuoba basalts near Zhangjiakou, and site localities are indicated by open circles in Fig. 1. Pan et al. (2005) reported a paleomagnetic and paleointensity study for an OligoceneMiocene lava sequence from the Hannuoba basalts. The site locality of their study is indicated by an open triangle in Fig. 1. The ages of the samples used in this study are in two groups of 6-8 Ma and 28-32 Ma, which are different from the age range of 15-24 Ma covered by the lava sequence of Pan et al. (2005).

Samples were selected based on high stability of remanence to AF and thermal demagnetization and the quality of other rock magnetic properties, including the small difference between the heating and cooling curves of magnetic susceptibility vs. temperature $(\chi-\mathrm{T})$ and saturation magnetization vs. temperature $\left(\mathrm{J}_{S}-\mathrm{T}\right)$. The nature of the domain 
Table 1. Site mean paleodirections and paleointensities.

\begin{tabular}{|c|c|c|c|c|c|c|c|c|c|c|c|c|}
\hline Site & $\begin{array}{l}\text { Slat } \\
\left({ }^{\circ} \mathrm{N}\right)\end{array}$ & $\begin{array}{l}\text { Slon } \\
\left({ }^{\circ} \mathrm{E}\right)\end{array}$ & $\begin{array}{l}\text { Age } \\
(\mathrm{Ma})\end{array}$ & $\mathrm{N}_{D}$ & I & D & $\alpha_{95}$ & $k$ & $\mathrm{~N}_{P}\left(\mathrm{~N} / \mathrm{N}_{0}\right)$ & $\begin{array}{c}\mathrm{F} \\
(\mu \mathrm{T})\end{array}$ & \multicolumn{2}{|c|}{$\left(10^{22} \mathrm{~A} \mathrm{~m}^{2}\right)$} \\
\hline CJ01-02 & 42.36 & 118.62 & $6.51 \pm 0.07$ & 10 & 54.5 & 355.0 & 2.4 & 405.2 & $4(5 / 9)$ & $53.9 \pm 8.9$ & $9.9 \pm 1.6$ & $9.1 \pm 1.5$ \\
\hline CSZ01 & 42.35 & 118.63 & $6.81 \pm 0.22$ & 8 & 55.4 & 7.0 & 3.3 & 279.9 & $6(6 / 6)$ & $57.1 \pm 10.7$ & $10.4 \pm 1.9$ & $9.6 \pm 1.8$ \\
\hline CX05 & 42.20 & 118.72 & $6.90 \pm 0.15$ & 8 & 57.8 & 357.9 & 2.4 & 554.2 & $3(3 / 5)$ & $72.1 \pm 30.0$ & & \\
\hline CX03 & 42.33 & 118.71 & $7.54 \pm 0.09$ & 7 & 55.9 & 355.2 & 2.4 & 640.9 & $1(2 / 5)$ & $101.4 \pm 5.6$ & & \\
\hline CS01 & 42.24 & 119.25 & $28.68 \pm 0.40$ & 8 & -56.3 & 231.1 & 1.7 & 1067.1 & $5(6 / 6)$ & $64.9 \pm 4.7$ & $11.6 \pm 0.9$ & $10.9 \pm 0.8$ \\
\hline ZY02 & 41.16 & 114.66 & $29.97 \pm 0.41$ & 8 & -47.3 & 186.0 & 7.1 & 63.4 & $4(4 / 9)$ & $22.8 \pm 2.5$ & $4.5 \pm 0.5$ & $3.9 \pm 0.4$ \\
\hline CD01 & 42.22 & 119.08 & $31.53 \pm 0.79$ & & & & & & $7(8 / 8)$ & $55.2 \pm 9.7$ & & $9.3 \pm 1.6$ \\
\hline
\end{tabular}

Note: Slat, Slon; latitude and longitude of the site location, Age; all data are from Zheng et al. (2002), $\mathrm{N}_{D}$; number of samples used for the site mean paleodirection, I, D, $\alpha_{95}, k$; all data are from Zheng et al. (1991) except for CJ01-02 which are combined from the original sample paleodirections, $\mathrm{N}_{P}\left(\mathrm{~N} / \mathrm{N}_{0}\right)$; number of samples used for the site mean paleointensity (numbers of successful/total specimens in the experiment), F, VDM, VADM; site means which are simple averages and the errors are standard deviations.

Site means of CX05 and CX03 were finally rejected because a large standard deviation of $42 \%$ was resulted in the former and only two specimens from the same sample were successful in the latter.

Paleodirection was not obtained from CD01 due to block rotation in the outcrop.

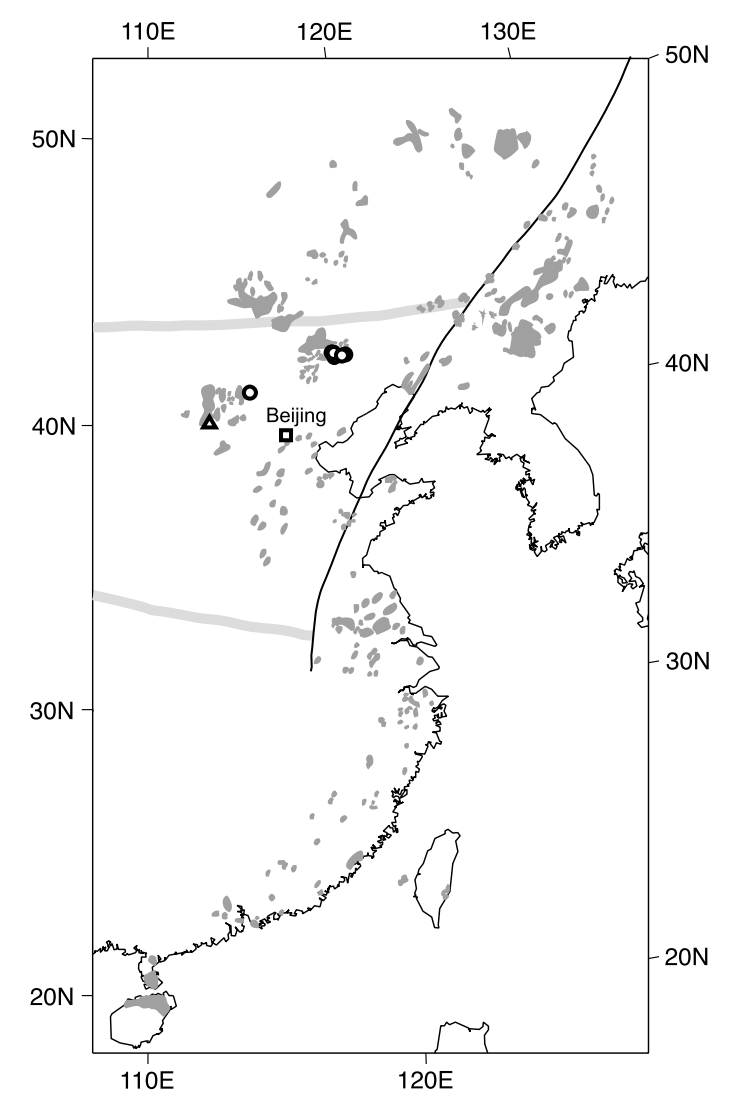

Fig. 1. Distribution of basaltic rocks in eastern China, which are mostly in Cenozoic age (re-drawn from Chen et al. (1990)). Grey thick lines are major tectonic boundaries, and a fine black line is a major fault (Tan-Lu Fault). Site localities in this study are shown by open circles, while the open triangle indicates the site of the lava sequence by Pan et al. (2005).

state of the magnetic minerals, determined from the magnetic hysteresis parameters, was also considered for sample selection. Those samples with SD (single domain) to PSD (pseudo-SD) nature were given higher priority.

Measurements of $\chi-T$ were made in air by a susceptibility-temperature system MS2 of Bartington Instruments Ltd. and those of $\mathrm{J}_{S}-\mathrm{T}$ were made in helium atmosphere by a vibration sample magnetometer Micromag 3900 of Princeton Measurements Corp. $\chi-\mathbf{T}$ and $\mathbf{J}_{S^{-}}$ $\mathrm{T}$ curves are roughly categorized into three classes based on the repeatability of the heating and cooling curves. The curves with the maximum difference of $\chi(J)$ of less than $15 \%, 15 \%-30 \%$, and more than $30 \%$ of the starting value are classified as class $\mathrm{A}, \mathrm{B}$, and $\mathrm{C}$, respectively. Representative $\chi-T$ and $J_{S}-T$ curves are shown in Fig. 2 in which solid red and dotted blue lines indicate heating and cooling curves, respectively, and the rows of the figure are arranged by class. From this figure, it is recognized that the difference between the heating and cooling curves are larger in $\chi$ - $\mathrm{T}$ curves than $\mathrm{J}_{S}$ - $\mathrm{T}$ curves for the samples from the same core. $\chi-\mathrm{T}$ curves from CS01 and CD01 are in Class $\mathrm{B}$, while $\mathrm{J}_{S}-\mathrm{T}$ curves from both lavas are in Class A. The $\chi$-T curve from ZL01 is Class $\mathrm{C}$, while $\mathrm{J}_{S}-\mathrm{T}$ curve from the same lava is Class B. Except for those from CJ01, $\mathrm{J}_{S^{-}}$ $\mathrm{T}$ curves show in general a better repeatability between the heating and cooling curves than $\chi$-T curves. Solely with this fact it is difficult to conclude that $\chi$ is more susceptible than $\mathrm{J}_{S}$ to chemical alteration during heating because the former measurements were made in air while helium atmosphere was used for the latter measurements. Nevertheless, $\chi$-T curves were generally better indicators for sample selection in the paleointensity experiments.

Of 17 flows examined, only five were categorized into Class $\mathrm{A}$ in both $\mathrm{J}_{S}$ and $\chi$-T measurements. Including other five flows which were in Class $\mathrm{A}$ in either $\mathrm{J}_{S}$ or $\chi$-T measurements, samples from a total of ten flows were used for the paleointensity experiments.

Figure 3 shows representative magnetic hysteresis curves (a-e) and the Day plot (Day et al., 1977) of the hysteresis parameters in log-log scale (f) in which small letters a-e correspond to those of the hysteresis curves (a)-(e). Crosses indicate those samples which were not used for paleointensity experiments. Circles are the results for the samples used in the experiments, where white, grey, and black circles show $100 \%, 60-40 \%$, and $0 \%$ flow success rate respectively (details are given in the next section). It is recognized that the success rate of the paleointensity experiments is not necessarily higher for the samples closer to the SD nature. 


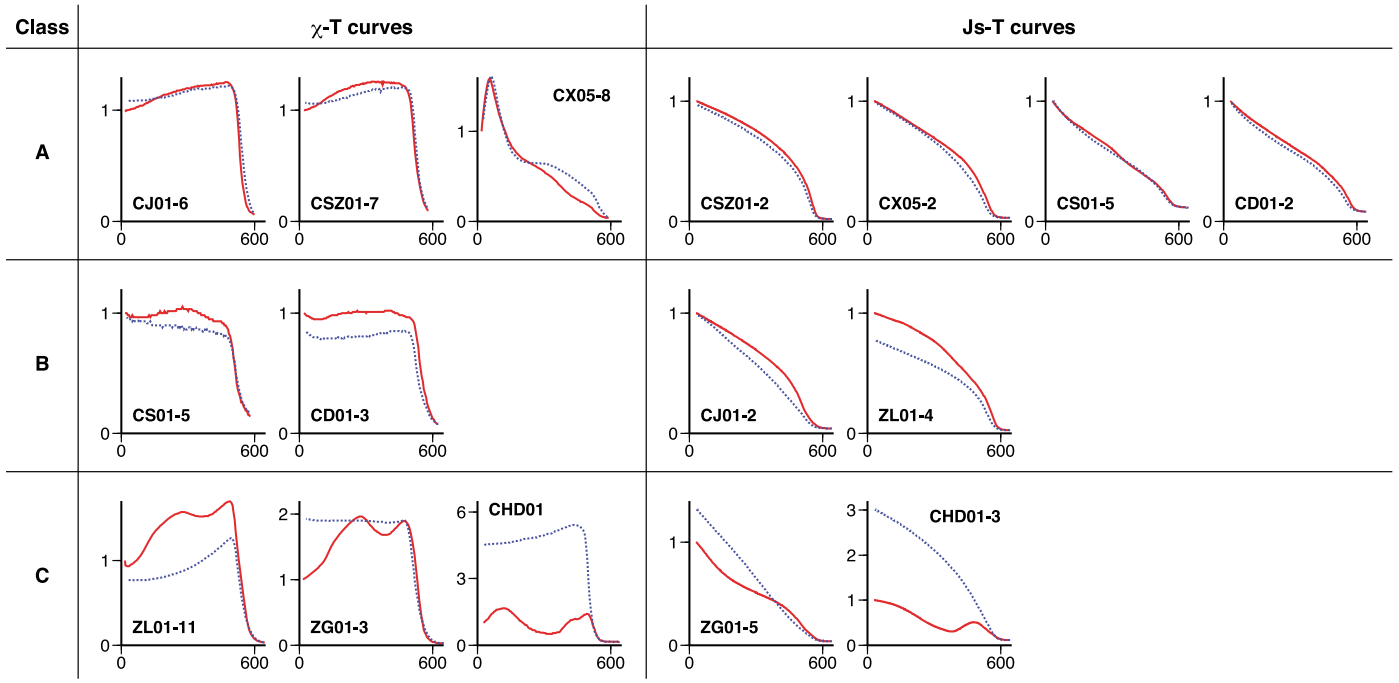

Fig. 2. Representative $\chi-\mathrm{T}$ and $\mathrm{J}_{S}-\mathrm{T}$ curves in which solid red and dotted blue lines indicate heating and cooling curves, respectively, and the rows of the figure are arranged by the class of the curves.
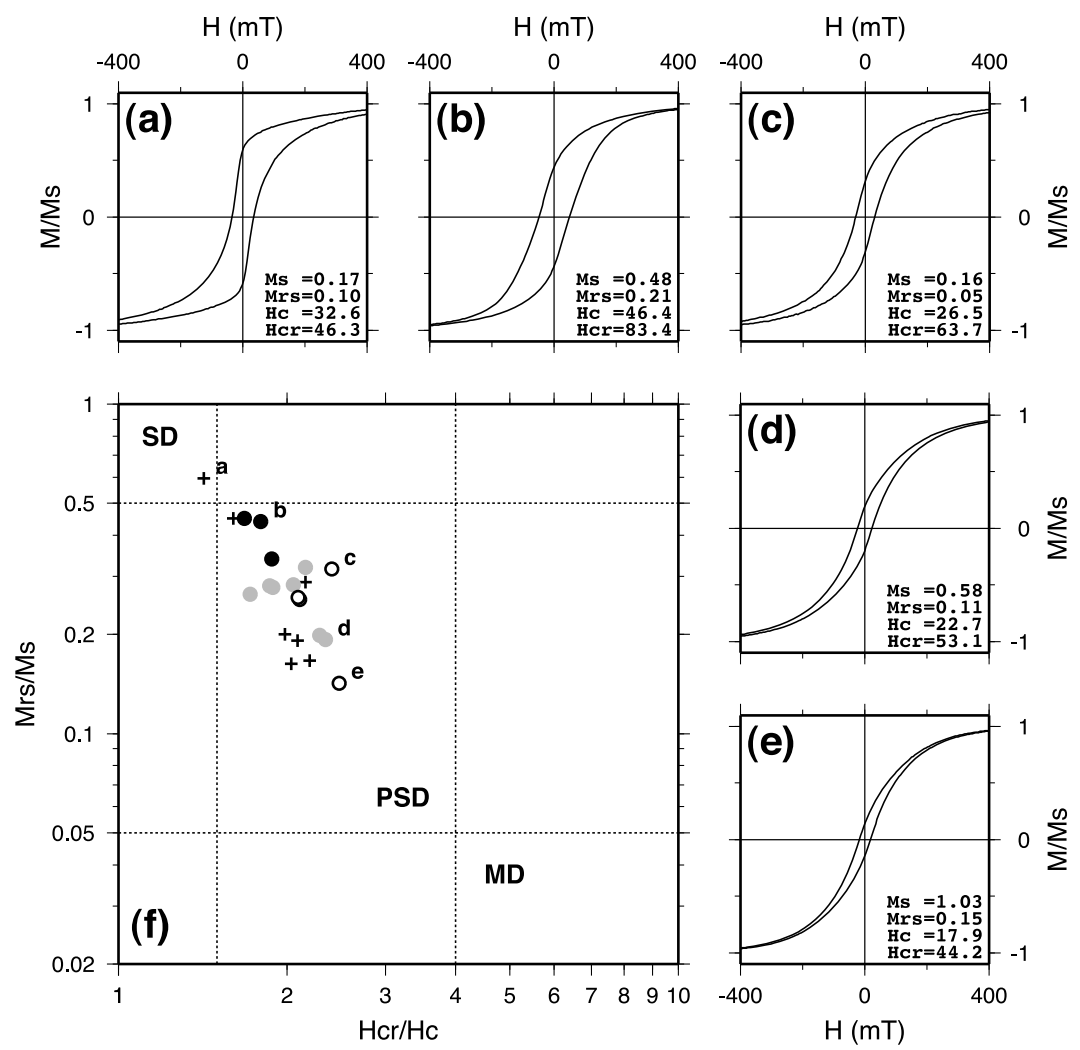

Fig. 3. Representative magnetic hysteresis curves in which the slope is corrected for the effect of paramagnetism (a-e) and the Day plot of the hysteresis parameters in log-log scale (f). Hysteresis parameters are tabled in each figure of (a)-(e) where the units are $\mathrm{A} \mathrm{m} / \mathrm{kg}$ for saturation magnetization (Ms) and saturation remanence (Mrs) and $\mathrm{mT}$ for coercivity $(\mathrm{Hc})$ and coercivity of remanence (Hcr). In the Day plot (f), lowercase letters a-e correspond to those of the hysteresis curves (a)-(e). Crosses indicate those of the samples which were not used in the paleointensity experiments. Circles are the results for the samples used in the experiments, where white, grey, and black circles show $100 \%, 60-40 \%$, and $0 \%$ flow success rate, respectively.

\section{Paleointensity Experiments}

Coe's modification (Coe et al., 1978) of the Thellier's method (Thellier and Thellier, 1959) was used for all experiments, which were carried out under a vacuum of about $5 \mathrm{~Pa}\left(\sim 5 \times 10^{-2}\right.$ Torr $)$. To detect any alteration occur- ring during the experiments, pTRM checks were made at every other step. The reason that the pTRM check was not made for all steps is to subdue any oxidation which might occur during heating. For the same reason, checks for multidomain (MD) tails of the pTRM (Riisager and Riisager, 

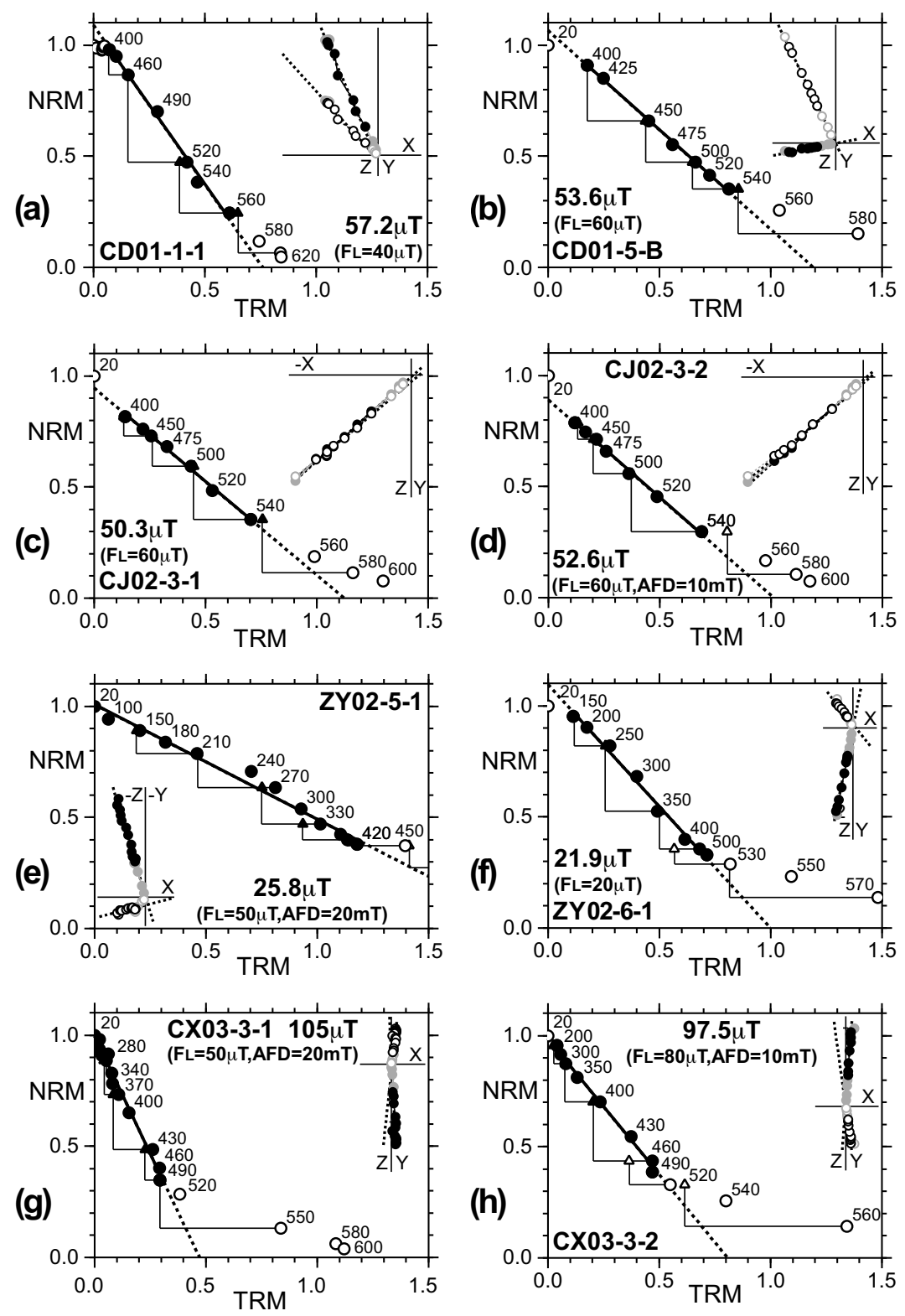

Fig. 4. Representative Arai plots of the Thellier's experiments. Solid symbols in the Arai plots are the data points included to the linear analysis. Triangles are data points of pTRM checks. Some samples were AF demagnetized at $10 \mathrm{mT}$ or $20 \mathrm{mT}$ after every step, which is indicated in the figure. An orthogonal diagram in each figure shows the NRM vectors for the zero-field steps in the sample frame, in which the laboratory field was induced along $+Z$ direction.

2001) were omitted. Results of the Thellier's experiments were analyzed on the Arai plot (Nagata et al., 1963). Acceptance criteria are basically after those by Kissel and Laj (2004); (1) the linear segment should include at least four points with a correlation coefficient $-r$ larger than 0.99 and a NRM fraction $f$ larger than 0.35 ; (2) pTRM test is positive, which is judged by a PTRM difference normalized by the length of the linear segment (DRAT) smaller than 7\% and its accumulation over the selected temperature interval (CDRAT) smaller than 10\%; (3) maximum angular deviation (MAD) of the NRM vector component corresponding to the selected linear segment is less than $7^{\circ}$ and reasonably decreases toward the origin on the orthogonal plot, which is judged by a difference angle $\alpha$ smaller than $10^{\circ}$. For the last criterion, less than $10 \%$ is also imposed to a deviation dev of Tanaka and Kobayashi (2003), which is a minimum distance of the fitted line of the NRM vector from the origin normalized by the NRM intensity.

Two series of experiments were made on a total of 54 specimens. First experiments included 28 specimens which were selected based on the rock magnetic evaluation mentioned before. In the second experiments, those flows which were unsuccessful in the first run were not used. In this way, 34 specimens were successful, giving a specimen level success rate of $63 \%$, but the final success rate was reduced to $54 \%$ by application of site level acceptance criteria. Reasons for the failure of experiments varied from specimen to specimen, but a low correlation coefficient less than 0.99 is the most frequent. Some results were not analyzed due to a two-segments Arai plot with a large initial decay of 


\section{NORMAL/REVERSE}
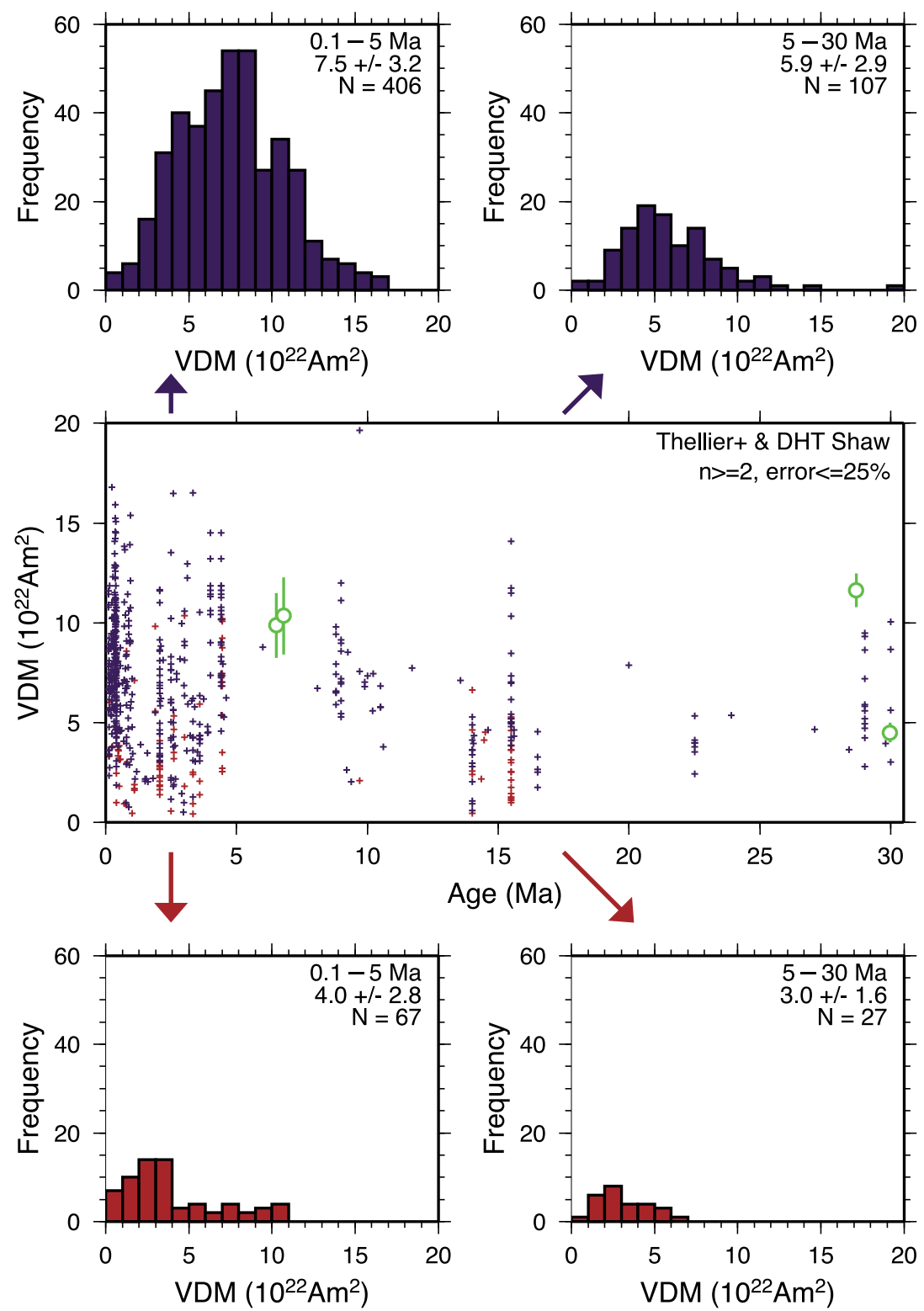

TRANSITION

Fig. 5. VDM versus age and their histograms for the last $30 \mathrm{~m} . \mathrm{y}$. Upper and lower histograms show VDM distributions during the polarity states of normal/reverse and transition, respectively. Two histograms for each of polarity states show those for the time periods of 0.1-5 Ma and 5-30 Ma. In the central figure of VDM vs. age, blue and red crosses indicate those in normal/reverse and transition, respectively. Green open circles are new data from this study (one result of $55 \mu \mathrm{T}$ from $31.5 \mathrm{Ma}$ lava is not included due to unavailability of paleodirection).

NRM intensity. All specimen level results are summarized in the Appendix where those of rejected are shown in reduced font.

Eight representative results from four flows are shown in Fig. 4 in which two examples from each flow with different experimental conditions are compared. In the figure, orthogonal plots of NRM direction for zero-field steps are also shown in the sample frame, in which the $+\mathrm{Z}$ axis is the direction of the laboratory field.

Figure 4(a) and (b) compare two results from the $31.5 \mathrm{Ma}$ basalt in which all of the eight specimens were successful. CD01-1-1 using a laboratory field of $40 \mu \mathrm{T}$ gave a result of $57.2 \mu \mathrm{T}$, which agrees well with the $53.6 \mu \mathrm{T}$ obtained from CD01-5-B with a laboratory field of $60 \mu \mathrm{T}$. A moderately large flow mean paleointensity of $55.2 \pm 9.7 \mu \mathrm{T}$ was obtained.

AF demagnetization (AFD) at $10 \mathrm{mT}$ or $20 \mathrm{mT}$ for every step was applied to 16 samples to see its effect in the Thellier's experiment, and two examples from the same core are shown in Fig. 4(c) and (d) from flow CJ02 (6.5 \pm 0.1 Ma). Arai plot of CJ02-3-2 with AFD (Fig. 4(d)) is compared to the result of CJ02-3-1 from the ordinary experiment (Fig. 4(c)). Results from the two experiments are in good agreement. However, the effectiveness of involving 
AFD is not conclusive because there were no results rescued by AFD which were otherwise rejected. The range of the decay rate of the original NRM was $0.87-0.96$ after 10 $\mathrm{mT}$ and $0.83-1.00$ after $20 \mathrm{mT}$, but no correlation was observed between the decay rate and the experimental results.

Figure 4(e) and (f) show two examples which gave low paleointensities from the $30.0 \pm 0.4$ Ma flow. Experimental results using a laboratory field of $50 \mu \mathrm{T}$ were not very good except for sample ZY02-5-1 which passed the criteria. When using a small laboratory field of $20 \mu \mathrm{T}$, however, the Arai diagram was much more reliable. It is noted that the small value of 25.8 $\mu \mathrm{T}$ from ZY02-5-1 is concordant with the more reliable results when using a small laboratory field.

Two examples from the $7.5 \pm 0.1 \mathrm{Ma}$ flow in which very large paleointensities were obtained are shown in Fig. 4(g) and (h). These two results, which were obtained using different laboratory fields, are in good agreement. Unfortunately, only these two results out of the five specimens passed the acceptance criteria. As these two successful specimens are from the same sample, these high paleointensities were finally rejected.

As mentioned before, in this study 28 specimens were selected for the first experiments based on the total evaluation which combines all of the qualities of the remanence stability and rock magnetism. In this sample selection, the quality of $\chi$-T curve was the most useful, as suggested in Fig. 2. After completion of the first experiments, those flows which revealed bad behavior were omitted from the sample selection for the second set of another 26 specimens, thereby concentrating more on those which were promising. Although 34 specimens out of 54 were successful in the experiments, two flow means were finally rejected, because in one flow the standard deviation amounted to a large value of $42 \%$ and in another flow only two specimens from the same sample survived. Nevertheless, the final success rate of $54 \%(29 / 54)$ attained in this study is reasonable, which is probably due to the above-mentioned scheme of sample selection.

\section{Discussion}

Site mean paleointensities are summarized in Table 1 in which the paleodirectional data are reproduced from Zheng et al. (1991), except for sites CJ01, CJ02, and CD01. Sample directions were combined for CJ01 and CJ02, which are only $50 \mathrm{~m}$ apart and considered to be from the same flow. Although the statistical test by McFadden and Lowes (1981) indicates that the two site means are significantly different, we believe that these are still the same flow because the negative statistical test is due to too small $\alpha_{95}$ observed at each site. The difference angle of $4.7^{\circ}$ between the mean directions, which is almost all in declination, could easily arise from an orientation error because at these sites the sun azimuth was not available (e.g., Tanaka et al., 2004).

An anomalous paleodirection of $\mathrm{I}=-44.2^{\circ}, \mathrm{D}=95.3^{\circ}$, $\alpha_{95}=11.6^{\circ}$ is obtained from CD01, which was not reported in Zheng et al. (1991). This is interpreted as an error in the sampling rather than a geomagnetic transition. Zheng et al. (1991) reported that samples were collected from an inclined block at some sites and that the block rotation was successfully corrected by the attitude of the columnar joint.
The anomalous paleodirection of CD01 is probably due to a similar block rotation, but it is impossible to restore the remanence directions because the attitude is not available. Hence, only a virtual axial dipole moment (VADM) was calculated from CD01.

The mean paleointensity of $72.1 \pm 30.0 \mu \mathrm{T}$ from CX05 was finally rejected due to a large standard deviation of $42 \%$. The site mean of $101.4 \pm 5.6 \mu \mathrm{T}$ from CX03 was also rejected because this is based on the results of two specimens which were taken from the same sample. The site mean data from these two sites are listed in smaller font in Table 1.

The five paleointensities obtained in this study are moderately large, ranging from $54 \mu \mathrm{T}$ to $65 \mu \mathrm{T}$ except for the $30 \mathrm{Ma}$ flow which has a small value of $23 \mu \mathrm{T}$. These new data have been compared with the Pint03 database. Data retrieved from Pint03 are only those that used the Thellier's method with pTRM checks (so-called $\mathrm{T}+$ data) and those obtained from at least two samples with a maximum flow mean standard deviation of $25 \%$. Data were also accepted that used the Shaw method which incorporates the double heating methodology of Tsunakawa and Shaw (1994). For data retrieved with these conditions, there are no entries in the age range between 30 and $50 \mathrm{Ma}$. Considering also the high data density for the time range younger than 0.1 $\mathrm{Ma}$, only those in the age range of 0.1-30 Ma were considered for comparison. New or missing data in Pint03 for this age range were added from the data in the literature (Bogue, 2001; Goguitchaichvili et al., 2002; Glen et al., 2003; Leonhardt et al., 2003; Carvallo et al., 2004; Tauxe et al., 2004a, b; Thomas et al., 2004; Chauvin et al., 2005; Herrero-Bervera and Valet, 2005; Hill et al., 2005; Pan et al., 2005; Yamamoto and Tsunakawa, 2005).

The virtual dipole moments (VDM) for $0.1-30 \mathrm{Ma}$ are summarized in Fig. 5 in which blue and red symbols/histograms represent for those from the polarity states of normal/reverse and transitional respectively. The histograms are shown separately for each of the time periods of 0.1-5 Ma and 5-30 Ma. The polarity state of each data was based on the polarity entries in the database which basically follow the author's statement in the original literature. Small VDMs dominate in the lower histograms of Fig. 5, and this simply ascertains the well-established smallness of the dipole moment during a transition (e.g., Merrill et al., 1996). The upper histograms in Fig. 5 indicate that there is a significant difference in the mean VDM between the two time periods of $0.1-5 \mathrm{Ma}$ and 5-30 Ma. The mean VDM for the former of $7.5 \pm 3.2\left(10^{22} \mathrm{Am}^{2}\right)$ is quite close to the present-day value while that for the latter is much smaller. Pan et al. (2005) suggested that the mean VDM for the Pliocene and late Miocene (2-15 Ma) is larger than that for the early Miocene and late Oligocene (15-30 Ma). Considering the rather large VDM for the 29 Ma lava in this study (together with the VADM from the 31.5 Ma lava which is not included in the figure), it is probably too early to conclude such a difference of the dipole moment. It is suggested that although the dipole moment was generally smaller than the present-day value in the time period of 5$30 \mathrm{Ma}$, it still showed large fluctuations. 
Appendix. Specimen results of paleointensity experiments

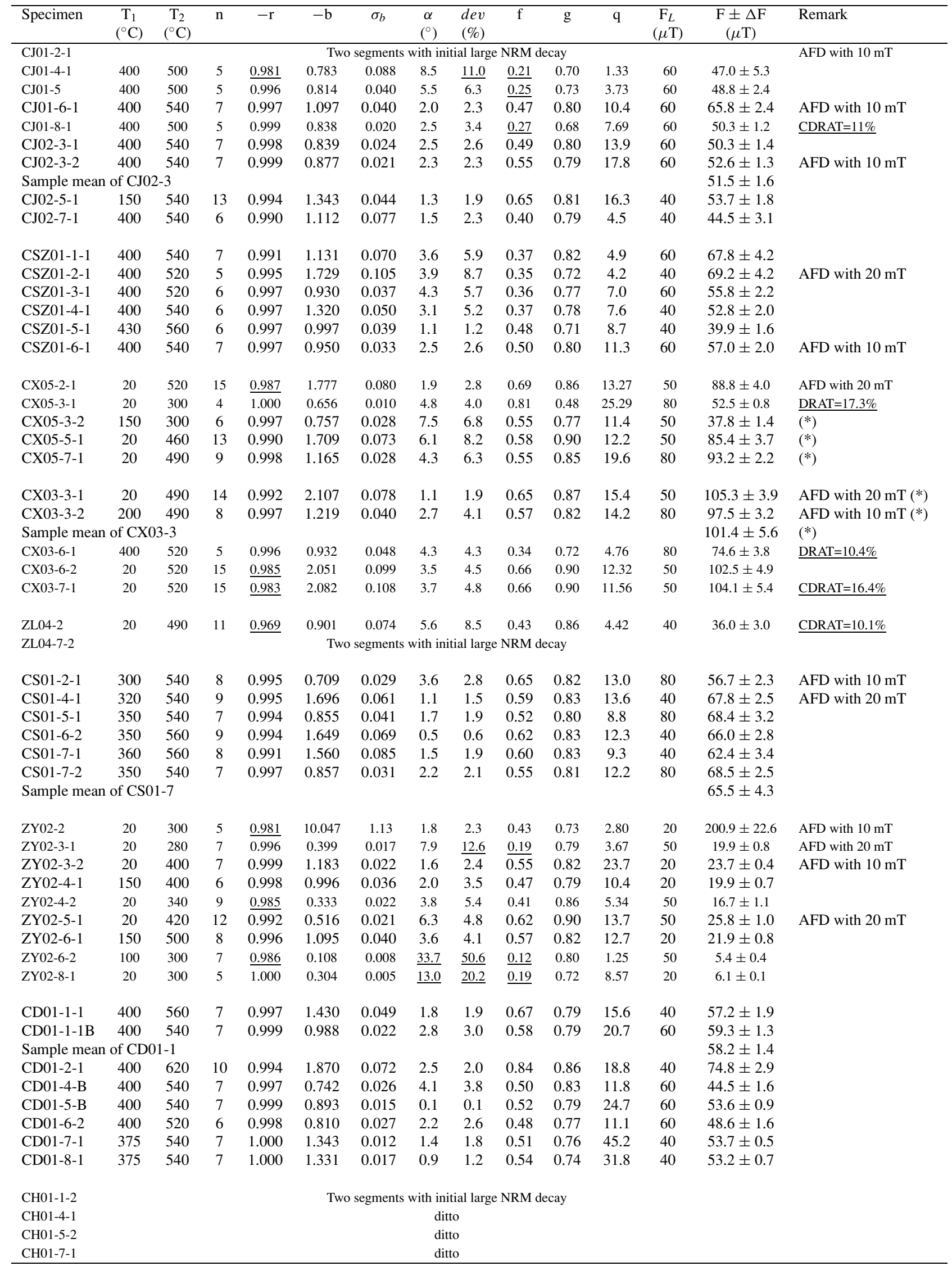

Note: $T_{1}, T_{2}$, lower and upper temperatures for the linear segment; $n$, number of data point included in the linear regression; $r$, correlation coefficient of the linear segment; b, slope of the segment; $\sigma_{b}$, standard error of $\mathrm{b} ; \alpha$, dev, difference angle and deviation of the selected NRM component from the origin on the orthogonal plot; f, g, q, quality parameters after Coe et al. (1978); $\mathrm{F}_{L}$, laboratory field strength; $\mathrm{F}$, $\Delta \mathrm{F}$, paleointensity and its standard error.

Results shown in reduced font are those rejected, where underlined values are the parameters lower than the minimum criterion.

(*) Results from CX05 and CX03 were finally rejected by application of site level acceptance criteria. 


\section{Conclusion}

Thellier's experiments were carried out on to Tertiary basalts in Inner Mongolia and Hebei Province, northeastern China. A sample selection scheme based on the total evaluation of the qualities of remanence stability and rock magnetism was effective giving the final success rate of $54 \%$. It was suggested that $\chi$-T curves are a better indicator for sample selection than $\mathrm{J}_{S}-\mathrm{T}$ curves because the effect of chemical alteration is more pronounced in the former although this might be due to the difference of furnace atmospheres. Among five flow mean paleointensities obtained, four range from 54 to $65 \mu \mathrm{T}$ and one is $23 \mu \mathrm{T}$. These results, combined with the Pint03 database updated with data from recent literature, indicate that there was a large fluctuation in the paleointensity which often attained the present-day level, although the Tertiary dipole moment was generally smaller.

Acknowledgments. Some of the rock magnetic measurements were made at the Institute for Study of the Earth's Interior, Okayama University while Masaru Kono had a professorship there, and we thank him for the use of paleomagnetic facilities. Rock magnetic measurements were also made at the Center for Advanced Marine Core Research, Kochi University, and we are grateful to Kazuto Kodama for use of rock magnetic facilities. We acknowledge constructive comments from two reviewers, Mimi Hill and Nobutatsu Mochizuki, which much improved the manuscript. This study was financially supported by Ministry of Education, Culture, Sports, Science, and Technology (MEXT) with a grant-in-aid for scientific research (13640424).

\section{References}

Biggin, A. J. and D. N. Thomas, Analysis of long-term variations in the geomagnetic poloidal field intensity and evaluation of their relationship with global geodynamics, Geophys. J. Int., 152, 392-415, 2003.

Bogue, S. W., Geomagnetic field behavior before and after the Kauai reverse-normal polarity transition, J. Geophys. Res., 106, 447-461, 2001.

Carvallo, C., Ö. Özdemir, and D. J. Dunlop, Palaeointensity determinations, palaeodirections and magnetic properties of basalts from the Emperor seamounts, Geophys. J. Int., 156, 29-38, 2004.

Chauvin, A., P. Roperch, and S. Levi, Reliability of geomagnetic paleointensity data: the effects of the NRM fraction and concave-up behavior on paleointensity determinations by the Thellier method, Phys. Earth Planet. Inter., 150, 265-286, 2005.

Cheng, H., Y. Tatsumi, and K. Ishizaka, Temporal and spatial distribution of Cenozoic basalts in eastern China, Reports on Earth Science, Department of General Education, Kyoto University, 24, December, 1-14, 1990 (in Japanese).

Coe, R. S., S. Grommé, and E. A. Mankinen, Geomagnetic paleointensities from radiocarbon-dated lava flows on Hawaii and the question of the Pacific nondipole low, J. Geophys. Res., 83, 1740-1756, 1978.

Day, R., M. Fuller, and V. A. Schmidt, Hysteresis properties of titanomagnetites: grain-size and compositional dependence, Phys. Earth Planet. Inter., 13, 260-267, 1977.

Glen, J. M. G., J.-P. Valet, V. Soler, P. R. Renne, and A. Elmaleh, A Neogene geomagnetic polarity transition from lavas of the Canary Islands, Spain: episodic volcanism and/or metastable transitional fields?, Geophys. J. Int., 154, 426-440, 2003.

Goguitchaichvili, A., L. Alva-Valdivia, J. Rosas-Elguera, J. UrrutiaFucugauchi, J. A. Gonzalez, J. Morales, and J. Sole, An integrated paleomagnetic study of Rio Grande de Santiago volcanic succession (transMexican volcanic belt): revisited, Phys. Earth Planet. Inter., 130, 175194, 2002.

Heller, R., R. T. Merrill, and P. L. McFadden, The two states of paleomagnetic field intensities for the past 320 million years, Phys. Earth Planet. Inter., 135, 211-223, 2003.

Herrero-Bervera, E. and J.-P. Valet, Absolute paleointensity and reversal records from the Waianae sequence (Oahu, Hawai, USA), Earth Planet. Sci. Lett., 234, 279-296, 2005.
Hill, M. J., J. Shaw, and E. Herrero-Bervera, Paleointensity record through the Lower Mammoth reversal from the Waianae volcano, Hawaii, Earth Planet. Sci. Lett., 230, 255-272, 2005.

Kissel, C. and C. Laj, Improvements in procedure and paleointensity selection criteria (PICRIT-03) for Thellier and Thellier determinations: application to Hawaiian basaltic long cores, Phys. Earth Planet. Inter., 147, 155-169, 2004.

Leonhardt, R., J. Matzka, and E. A. Menor, Absolute paleointensities and paleodirections of miocene and pliocene lavas from Fernando de Noronha, Brazil, Phys. Earth Planet. Inter., 139, 285-303, 2003.

McFadden, P. L. and F. J. Lowes, The discrimination of mean directions drawn from Fisher distributions, Geophys. J. R. astr. Soc., 67, 19-33, 1981.

Merrill, R. T., M. W. McElhinny, and P. L. McFadden, The Magnetic Field of the Earth, 527 pp., Academic Press, San Diego, 1996.

Nagata, T., Y. Arai, and K. Momose, Secular variation of the geomagnetic total force during the last 5000 years, J. Geophys. Res., 68, 5277-5281, 1963.

Pan, Y., M. J. Hill, and R. Zhu, Paleomagnetic and paleointensity study of an Oligocene-Miocene lava sequence from the Hannuoba Basalts in northern China, Phys. Earth Planet. Inter., 151, 21-35, 2005.

Perrin, M. and E. Schnepp, IAGA paleointensity database: distribution and quality of the data set, Phys. Earth Planet. Inter., 147, 255-267, 2004.

Riisager, P. and J. Riisager, Detecting multidomain magnetic grains in Thellier palaeointensity experiments, Phys. Earth Planet. Inter., 125, 111-117, 2001.

Selkin, P. A. and L. Tauxe, Long-term variations in palaeointensity, Phil. Trans. Roy. Soc. Lond. A., 358, 1065-1088, 2000.

Tanaka, H. and T. Kobayashi, Paleomagnetism of the late Quaternary Ontake Volcano, Japan: directions, intensities, and excursions, Earth Planets Space, 55, 189-202, 2003.

Tanaka, H. and M. Kono, Paleointensities from a Cretaceous basalt platform in Inner Mongolia, northeastern China, Phys. Earth Planet. Inter., 133, 147-157, 2002.

Tanaka, H., M. Kono, and H. Uchimura, Some global features of paleointensity in geological time, Geophys. J. Int., 120, 97-102, 1995.

Tanaka, H., H. Hoshizumi, Y. Iwasaki, and H. Shibuya, Applications of paleomagnetism in the volcanic field: A case study of the Unzen Volcano, Japan, Earth Planets Space, 56, 635-647, 2004.

Tauxe, L., P. Gans, and E. A. Mankinen, Paleomagnetism and ${ }^{40} \mathrm{Ar} /{ }^{39} \mathrm{Ar}$ ages from volcanics extruded during the Matuyama and Brunhes Chrons near McMurdo Sound, Antarctica, Geochem. Geophys. Geosystems, 5 , GC000656, 2004a.

Tauxe, L., C. Luskin, P. Selkin, P. Gans, and A. Calvert, Paleomagnetic results from the Snake River Plain: Contribution to the time-averaged field global database, Geochem. Geophys. Geosystems, 5, GC000661, 2004 b.

Thellier, E. and O. Thellier, Sur l'intensité du champ magnetique terrestre dans le passé historique et géologique, Ann. Geophys., 15, 285-376, 1959.

Thomas, D. N., M. J. Hill, and A. S. Garcia, Comparison of the CoeThellier-Thellier and microwave palaeointensity techniques using hightitanium titanomagnetites: results from a Tertiary basaltic intrusion from the Sydney Basin, New South Wales, Earth Planet. Sci. Lett., 229, 1529, 2004.

Tsunakawa, H. and J. Shaw, The Shaw method of palaeointensity determinations and its application to recent volcanic rocks, Geophys. J. Int., 118, 781-787, 1994.

Yamamoto, Y. and H. Tsunakawa, Geomagnetic field intensity during the last 5 Myr: LTD-DHT Shaw palaeointensities from volcanic rocks of the Society Islands, French Polynesia, Geophys. J. Int., 162, 79-114, 2005.

Zhao, X., P. Riisager, J. Riisager, U. Draeger, R. S. Coe, and Z. Zheng, New paleointensity results from Cretaceous basalt of Inner Mongolia, China, Phys. Earth Planet. Inter., 141, 131-140, 2004.

Zheng, Z., M. Kono, H. Tsunakawa, G. Kimura, Q. Wei, X. Zhu, and T. Hao, The apparent polar wander path for the North China Block since the Jurassic, Geophys. J. Int., 104, 29-40, 1991.

Zheng, Z., H. Tanaka, Y. Tatsumi, and M. Kono, Basalt platforms in Inner Mongolia and Hebei Province, northeatern China: New K-Ar ages, geochemistries, and revision of palaeomagnetic results, Geophys. J. Int., 151, 654-662, 2002.

H. Tanaka (e-mail: htanaka@kochi-u.ac.jp), N. Takahashi, and Z. 